Two sides to the brain

John J. Sidtis

Human Cerebral Asymmetry.

By John L. Bradshaw and Norman

C. Nettleton.

Prentice-Hall: 1983. Pp.335. \$24.95, £22.45.

OVER the past twenty-five years, a feature of neuropsychology has been an enduring interest in the functional differentiation of the human cerebral hemispheres. Beginning with the early attempts to model a functional architecture of the brain based on clinical observations, experimental studies have gone on to delineate component processes as the province of one cerebral hemisphere or the other.

Such studies led to new general descriptions of the functional properties of the two hemispheres. Whereas the neurological distinctions of major versus minor, and dominant versus non-dominant were based on the observation that language is typically represented in a single hemisphere, usually the left, new distinctions such as verbal versus non-verbal and analytic versus holistic acknowledge the fact that the non-language hemisphere is dominant for some non-linguistic functions. Hemispheric differences have also attracted popular interest, frequently because of wild promises that hidden skills, untapped creativity or inner peace could be obtained simply by unleashing one's non-verbal hemisphere.

Given the attention paid to the differences in the two sides of the brain, it is quite surprising that until recently there were no introductory books on the topic. There are now several, with Bradshaw and Nettleton's Human Cerebral Asymmetry providing the broadest perspective. The authors cover the major topics such as how asymmetrical brain function can be observed through perceptual asymmetries in vision, audition and touch; the role of development in cerebral asymmetry; the possible genetic determination of cerebral asymmetry; and the evidence that there are sex differences in the degree of cerebral asymmetry. In addition, there is careful and balanced consideration of other topics, such as functional brain asymmetries in animals and morphological brain asymmetries in humans that are frequently presented in secondary sources in a way that exaggerates their relevance to functional cerebral asymmetry in humans.

The authors are at their best in discussing the wide range of studies on human subjects, the population they have been most involved with in their own research. Work on people with neurological damage is covered only nominally, the emphasis being on language dysfunction. The chapter on that topic begins with some

reasonable caveats regarding the interpretation of neurological data, then proceeds to a section on clinical techniques dealing with the establishment of hemispheric dominance for language. A useful addition here, and to the book as a whole, would have been an account of the most important clinical technique, the neurological examination. Neuropsychology has grown as much from clinical neurology as it has from experimental psychology, and in spite of the uncertainties inherent in studying clinical populations, the nature of the enterprise means that theories about brainbehaviour relationships derived from the study of normal subjects must eventually be validated in neurological populations.

The book's weakest point is in the coverage of the work on patients who have undergone surgical separation of the cerebral hemispheres for the control of

\section{Palaeontology by the telephone book}

\section{D.V. Ager}

\section{Fossil Invertebrates.}

By U. Lehmann and G. Hillmer.

Translated by Janine Lettau.

Cambridge University Press: 1983.

Pp.355. Hbk £20, \$39.50;

pbk $£ 7.50, \$ 13.95$.

"FACTS are essential" said Michael Stapleton in his recent volume on English literature, but "a guide who never makes a comment makes a dull companion'. That's how I feel about this book. I know that some of my palaeontology is now a little taxonomically dated and I'm not too sure about the Lychniskida and the Caudofoveata, but I am surprised to see memories of the past such as the Class Lamellibranchia (to say nothing of quaint old terms such as "Dogger" and "Malm").

This is a thorough work of German scholarship; in fact it out-Zittels Zittel, though at much shorter length. One may ask if it is needed these days with R.C. Moore's vast Treatise on Invertebrate Paleontology and the fat American, French and Russian volumes that continue to pour upon us, but it is in many ways more up to date and the best treatise in the world inevitably become dated as soon as it is published. I have not seen the original German version, but the translation seems competent and not unduly stiff, without adapting itself to many of the usages of English-speaking palaeontology and stratigraphy.

Although it is called Fossil Invertebrates, the book goes beyond the animal kingdom in the usual sense, at least in the microscopic field, by including several groups of algae, bacteria, the fungi (certainly not one of the more obvious epilepsy. Unfortunately, Bradshaw and Nettleton have limited themselves in many instances to the results obtained from two patients in a single surgical series. Moreover, a long section is given over to an account of several testing techniques that have not contributed substantially to understanding either the split-brain or normal cerebral asymmetry.

In general, though, Bradshaw and Nettleton have written an excellent introduction to the wide range of subjects that constitute the study of how function is represented in the two hemispheres of the brain. Human Cerebral Asymmetry is commendable for its style, balance and thoughtful presentation.

John J. Sidtis is an Assistant Professor of Psychology in Neurology at Cornell University Medical College, and a Professional Associate at the New York Hospital.

fossil groups) and even the Acritarchs and the Chitinozoa. This makes it more useful if a little confusing, as does the placing of some of the groups (the conodonts, for example, come between the brachiopods and the echinoderms).

Apart from a brief section on the origin of life, there is very little on evolution, or palaeoecology, or functional morphology, or geographical distribution or any of a dozen other subjects that many of us find so fascinating. No doubt that makes it the more scientific in a purely descriptive sense; it also - regrettably - makes it extremely dull. This is wholeheartedly a reference book in systematic palaeontology, not a book to read. It is not large enough to tackle genera, like Zittel or Moore, so it has to concentrate higher up the hierarchical scale. Many of us will probably think that this makes it less scientific rather than more so, since the only biological reality (difficult though it may be) is the species, and the rest are man-made fictions. I would argue, for example, (though perhaps it is a personal idiosyncrasy) about the validity of the Spiriferida as a natural division of the organic world. Other specialists would doubtless disagree about other groups.

What is this book for? Who reads telephone directories? At least it will be useful to me in understanding the examination questions of some of my younger colleagues, but where is the excitement of the subject that I found so long ago in Hawkins and Swinnerton, and so much later in Raup and Stanley? I write this review in hospital so I crave forgiveness for any drug-induced sourness that may have crept in; but this really is not a very inspiring palaeontological text and certainly not one that I would press upon either student or researcher.

Derek Ager is Professor and Head of the Department of Geology at University College, Swansea. 